\title{
Weight trajectories in women receiving systemic adjuvant therapy for breast cancer
}

\author{
Kirsten A. Nyrop ${ }^{1,5}$ (D) Allison M. Deal ${ }^{1} \cdot$ Shlomit S. Shachar ${ }^{4}$. Jihye Park ${ }^{2} \cdot$ Seul Ki Choi ${ }^{2} \cdot$ Jordan T. Lee $^{3}$. \\ Erin A. O'Hare ${ }^{1} \cdot$ Amy Wheless $^{1} \cdot$ Lisa A. Carey ${ }^{1} \cdot$ Hyman B. Muss $^{1}$
}

Received: 19 August 2019 / Accepted: 12 November 2019 / Published online: 16 November 2019

\begin{abstract}
Background Weight gain after breast cancer (BC) diagnosis is a well-known phenomenon; however, it is not a universal phenomenon and identification of patients at highest risk for weight gain is needed. This study investigates weight trajectories in early BC patients at 2 years post-primary treatment, examining potential contributing factors such as age, race, and receipt of chemotherapy, anti-HER-2 therapy, and endocrine treatment (ET).

Methods A single institution cohort of newly diagnosed women age 21 and older with early breast cancer patients (Stage 0-3) were identified by retrospective chart review (diagnosis year 1995 to 2016). Log-binomial regression models for net weight changes at 2 years post-primary treatment including patient demographic, clinical, and treatment characteristics.

Results The final sample of 625 patients included $29 \%$ who were non-White and 37\% who were pre-menopausal at diagnosis. Body mass index (BMI) at diagnosis was calculated and found to be normal in 33\% (BMI 18 to <25), overweight in 27\% (BMI 25 to <30), and obese in 40\% (BMI 30 and higher). At 2 years, compared to weight at diagnosis, $31 \%$ had lost $>2 \mathrm{~kg}$, $34 \%$ had stable weight $\pm 2 \mathrm{~kg}$, and $35 \%$ had gained $>2 \mathrm{~kg}$. Factors associated with $>2 \mathrm{~kg}$ weight gain were menopausal status (pre-menopausal HR 1.65, 95\% CI 1.34-2.04, $p<.0001$ ), receiving any chemotherapy (HR 1.36, 95\% CI 1.04-1.77), and anthracycline-based chemotherapy followed by ET (HR 1.60, CI 1.01-2.45). Anti-HER-2 therapy and transition from pre- to post-menopausal during the 2-year study period were not significant factors in weight gain. In multivariate analysis, menopausal status remained the only significant variable related to weight gain when adjusted for treatment. For all treatment combinations, pre-menopausal women had significantly more weight gain.
\end{abstract}

Conclusions and relevance Weight gain, weight loss, and stable weight in women with early breast cancer vary greatly by treatment plan. However, pre-menopausal patients have the highest risk for weight gain.

Keywords Breast cancer · Weight trajectories · Treatment regimens

Electronic supplementary material The online version of this article (https://doi.org/10.1007/s10549-019-05501-8) contains supplementary material, which is available to authorized users.

Kirsten A. Nyrop

kirsten_nyrop@med.unc.edu

1 Lineberger Comprehensive Cancer Center, University of North Carolina at Chapel Hill, Chapel Hill, NC, USA

2 Gillings School of Global Public Health, University of North Carolina at Chapel Hill, Chapel Hill, NC, USA

3 Department of Exercise and Sport Science, University of North Carolina at Chapel Hill, Chapel Hill, NC, USA

4 Rappaport Faculty of Medicine, Technion, Haifa, Israel

5 Division of Hematology-Oncology, University of North Carolina at Chapel Hill, 170 Manning Drive, Campus Box 7305, Chapel Hill, NC 27599, USA

\section{Introduction}

Weight gain is a common occurrence in women with early breast cancer, affecting an estimated $50-96 \%$ of survivors [1-6]. Initial interest in weight trajectories was sparked by the identification of chemotherapy as a risk factor for weight gain in breast cancer survivors in the 1970s [7, 8] and widely documented in studies published prior to 2000 $[3,6]$. Although less dramatic, weight gain continues to be observed with the newer chemotherapy regimens $[6,9]$, especially in patients receiving longer durations of treatment $[5,10]$ and anthracycline-based chemotherapy [11]. One study with 3 years of post-diagnosis follow-up reported continued weight gain in each successive year associated 
with having chemotherapy compared to no chemotherapy [12].

In light of growing evidence of an obesity-cancer connection [13-16], both oncologists and women with breast cancer are interested in knowing what, if any impact, different components of the overall treatment plan might have on weight trajectories in survivorship. There is a need to update older studies of weight trajectories using a contemporary sample of patients receiving chemotherapy regimens commonly used in current clinical practice. And, there is a need to consider the potential impact of non-chemotherapy components of the overall treatment plan including anti-HER-2 therapy and adjuvant endocrine treatment (ET), as well as various combinations of chemotherapy regimens and ET.

Our study investigates these questions in a large sample of women with early breast cancer treated in a single academic medical center, and who were followed from diagnosis through 2 years after completion of their primary treatment (surgery, chemotherapy, radiation). We build on our prior research regarding weight trajectories in women with early breast cancer which was limited to patients with hormone receptor-positive (HR+) tumors [17, 18]. In those prior studies, we reported that $49 \%$ of pre-menopausal and $38 \%$ of post-menopausal patients gained $>2 \mathrm{~kg}$ from onset of ET through the first 2 years of ET. In unadjusted analysis, younger age at diagnosis, pre-menopausal status at diagnosis, higher breast cancer stage, mastectomy, axillary lymph node surgery, neoadjuvant chemotherapy, and weight loss prior to start of ET were significant risk factors for $>2 \mathrm{~kg}$ weight gain during ET. In multivariable analysis, only weight loss between breast cancer diagnosis and the start of ET - a period that includes surgery and frequently radiation and/or chemotherapy-remained significant for risk of weight gain during ET [18].

For the current study, we have expanded our sample to include patients with HR negative tumors. In this large and well-annotated cohort, we examined weight trajectory associations with age, race, receipt of specific chemotherapy regimens, anti-HER-2 therapy, and endocrine therapy (tamoxifen and aromatase inhibitors). We conducted a detailed comparison of women who were pre-menopausal at diagnosis with women who were post-menopausal. The time frame is net weight change from diagnosis until 2 years postprimary treatment, defined as after surgery, chemotherapy and/or radiation treatment, whatever was last.

\section{Methods}

Our database was derived from patients seen consecutively in breast cancer clinics at a university-affiliated hospital center. To build our sample, we reviewed daily clinic schedules for patients who met the following eligibility criteria: female, age 18 or older, early stage breast cancer (Stage $0-3)$, detailed treatment information, weight data in the electronic health record (EHR) from breast cancer diagnosis through 2 years post-primary treatment, and no evidence of breast cancer recurrence, progression or metastasis during our study period. Patients could be at any point in their follow-up years; 8\% were diagnosed between 1996 and 2005 and $92 \%$ between 2005 and 2016. Menopausal status was determined from clinician notes when a treatment plan that includes endocrine treatment was presented to the patient and/or when initiation of ET was discussed with the patient. For patients who were not scheduled to receive endocrine treatment, clinician notes were searched beyond these time points for comments pertaining to ovarian suppression, fertility plans or transitions in menopausal status. Women age 50 and above were assumed to be post-menopausal.

To augment our database of consecutive patients with women whose tumors were either triple negative or HER-2 positive/HR negative, we included participants in the Neoadjuvant Database of the UNC Lineberger Comprehensive Cancer Center (LCCC9815, IRB 01-1154). Breast cancer diagnosis dates for the patients in our sample range from 1996 to 2016. Further details regarding our sampling methodology and best practice in retrospective chart review have been published elsewhere [17, 18]. The study was approved by the Institutional Review Board of the University of North Carolina (UNC) (IRB 15-1523).

\section{Measures}

Participant characteristics extracted from the EHR were selected a priori for their potential association with weight gain. Height and weight measures were taken during routine clinic visits by nursing staff using clinic-standardized procedures and recorded in the EHR. Weight-related time points of interest for the current analysis were weight at breast cancer diagnosis and 2 years post-primary treatment-net weight change between these two points in time. Our primary outcome measure is weight change in patients that was $>2 \mathrm{~kg}$ above weight at breast cancer diagnosis, compared to patients whose weight was stable $\pm 2 \mathrm{~kg}$ or those who lost weight $>2 \mathrm{~kg}$. All data were entered into a REDCap database [19]. Data extraction and entry was conducted by three co-authors (JTL, EAO and AW), with training and data quality control provided by three co-authors (AMD, SSS and KAN).

\section{Statistical considerations}

Descriptive statistics are used to characterize the sample and summarize weight change over time. Unadjusted log-binomial regression models are used to estimate relative risks of weight gain $>2 \mathrm{~kg}$ at 2 years with patient demographic, 
clinical, and treatment characteristics. All analyses were conducted using SAS Software Version 9.3 (SAS Institute Inc., Cary NC).

\section{Results}

\section{Patient characteristics}

Table 1 provides an overview of patient characteristics. The sample includes 625 women, $29 \%$ non-White, and 37\% premenopausal at breast cancer diagnosis. BMI distribution at diagnosis showed that $33 \%$ were normal (BMI 18.5 to $<25$ ), $27 \%$ overweight (BMI 25 to $<30$ ), $21 \%$ obese I (BMI 30 to $<35$ ), and $19 \%$ obese II (BMI 35 or higher). Seventy-six percent received radiation therapy, $72 \%$ chemotherapy, and $72 \%$ endocrine therapy. Among patients who received chemotherapy, most received anthracycline-based chemotherapy (75\%) and neoadjuvant chemotherapy (63\%). Twenty-seven percent received chemotherapy only and $28 \%$ received ET only.

\section{Pre-compared to post-menopausal patients}

Important differences in breast cancer diagnosis and treatment characteristics of pre-menopausal and post-menopausal patients are seen in Online Appendix 1. Pre-menopausal patients include a higher proportion with Stage 2 or 3 tumors $(p=.0001)$, lower proportion HR+ tumors $(p=.001)$, and lower proportion HR positive/HER-2 negative $(p=.007)$. Pre-menopausal patients also include a higher proportion receiving chemotherapy $(p<.0001)$, neoadjuvant chemotherapy $(p=.0003)$, anthracycline-based chemotherapy $(p<.0001)$, and higher proportion receiving chemotherapy without endocrine treatment $(p=.0006)$. Post-menopausal women, in turn, include a higher proportion receiving endocrine treatment alone, without chemotherapy $(p<.0001)$.

\section{Weight change from breast cancer diagnosis to 2 years post-primary treatment}

At 2 years post-primary treatment, $31 \%$ had lost $>2 \mathrm{~kg}, 34 \%$ had stable weight $\pm 2 \mathrm{~kg}$, and $35 \%$ had gained $>2 \mathrm{~kg}$. Histograms illustrating weight change in $2 \mathrm{~kg}$ increments are presented in Fig. 1. Weight gain $>2 \mathrm{~kg}$ was observed in $47 \%$ of pre-menopausal and $28 \%$ in post-menopausal patients; weight loss was observed in 34-35\% for both groups of patients. Weight gain within 2 years ranged up to $16 \mathrm{~kg}$ for post-menopausal and $24 \mathrm{~kg}$ for pre-menopausal patients, while weight loss was up to $19 \mathrm{~kg}$ in both groups. Among patients who were pre-menopausal at breast cancer diagnosis, $53 \%$ of those who transitioned to post-menopausal during the study period gained $>2 \mathrm{~kg}$ compared to $40 \%$ of those who remained pre-menopausal $(p=.09)$.

The relationship of BMI at baseline and weight change at 2 years is shown in Fig. 2. The y-axis represents BMI category at breast cancer diagnosis and the colors represent BMI category at 2 years post-diagnosis. Of note, $81 \%$ of patients (77\% pre-menopausal, $85 \%$ post-menopausal) who were at normal weight at baseline remained at normal weight at 2 years. In addition, $26 \%$ of pre-menopausal and $16 \%$ of post-menopausal patients lost weight to transition from obese II to obese I, while $19 \%$ in both menopausal groups transitioned from obese I to overweight. Conversely, $68 \%$ of pre-menopausal and $41 \%$ of post-menopausal patients transitioned into higher BMI categories. None of the women who were normal weight at diagnosis transitioned to underweight $(\mathrm{BMI}<18.5)$.

\section{Relative risk for weight gain over 2 years}

In Table 2, we present weight loss $>2 \mathrm{~kg}$, stable weight $\pm 2 \mathrm{~kg}$, and weight gain $>2 \mathrm{~kg}$ by patient characteristics. The relative risk for weight gain was 1.65 (CI $1.34,2.04)(p<.0001)$ in pre-menopausal compared to post-menopausal patients, 1.36 (CI 1.04, 1.77) in patients receiving any chemotherapy compared to no chemotherapy, and 1.60 (CI 1.01, 2.54) $(p=.04)$ in patients who received anthracycline-based chemotherapy plus endocrine therapy compared to non-anthracycline-based chemotherapy plus ET. Patients who received any endocrine therapy had lower risk for $>2 \mathrm{~kg}$ weight gain compared to patients who did not receive ET (RR .78, 95\% CI .62, .97) $(p=.02)$. Anti-HER-2 therapy was not associated with weight gain $(p=.31)$. In multivariable analysis, pre-menopausal status was the only variable that remained independently significant.

\section{Pre-compared to post-menopausal patients}

To explore menopausal status further, we analyzed the impact of menopausal status within individual treatment plans. As shown in Online Appendix 1, post-menopausal women have lower stage cancer, include a higher proportion who are $\mathrm{HR}+$, and include a higher proportion who receive any ET. In turn, pre-menopausal women have higher stage cancer and include a higher proportion of women who receive anthracycline-based chemotherapy with or without endocrine therapy. As shown in Fig. 3, across all treatment plans, pre-menopausal patients had a higher proportion experiencing $>2 \mathrm{~kg}$ weight gain compared to post-menopausal patients. Figure 3 also shows that, within individual treatment plans, patients can also lose weight or maintain their weight $\pm 2 \mathrm{~kg}$. The risk for $>2 \mathrm{~kg}$ weight gain is significantly greater in pre-menopausal compared to post-menopausal 
Table 1 Study participant characteristics at diagnosis $(N=625)$

\begin{tabular}{|c|c|}
\hline Variable & All $(N=625)$ \\
\hline Age at $\mathrm{BC}$ diagnosis & $\begin{array}{l}56(\text { SD } 12.7) \\
\text { Range } 25 \text { to } 88\end{array}$ \\
\hline \multicolumn{2}{|l|}{ Menopausal status } \\
\hline Pre-menopausal & $191(36 \%)$ \\
\hline Post-menopausal & $342(64 \%)$ \\
\hline Race: white & $443(71 \%)$ \\
\hline Marital status: married & $316(66 \%)$ \\
\hline Employment status: currently employed & $261(56 \%)$ \\
\hline Weight at breast cancer diagnosis $(\mathrm{kg})$ & $\begin{array}{l}78 \text { (SD 18.4) } \\
\text { Range } 44 \text { to } 150\end{array}$ \\
\hline Body Mass Index (mean, SD) at BC diagnosis & $\begin{array}{l}29(\mathrm{SD} 6.7) \\
\text { Range } 18 \text { to } 59\end{array}$ \\
\hline Normal $(18.5$ to $<25)$ & $207(33 \%)$ \\
\hline Overweight $(25$ to $<30)$ & $171(27 \%)$ \\
\hline Obese I ( 30 to <35) & $131(21 \%)$ \\
\hline Obese II ( 35 and above) & $116(19 \%)$ \\
\hline \multicolumn{2}{|l|}{ Breast cancer stage } \\
\hline 0 & $5(1 \%)$ \\
\hline 1 & $177(29 \%)$ \\
\hline 2 & $277(46 \%)$ \\
\hline 3 & $146(24 \%)$ \\
\hline HER-2 positive & $99(16 \%)$ \\
\hline Hormone receptor (HR) positive & $511(82 \%)$ \\
\hline \multicolumn{2}{|l|}{ Breast cancer phenotype } \\
\hline HR+/HER2- & $430(69 \%)$ \\
\hline HR-/HER2- & $88(14 \%)$ \\
\hline $\mathrm{HR}+/ \mathrm{Her} 2+$ & $73(12 \%)$ \\
\hline HR-/HER2+ & $26(4 \%)$ \\
\hline \multicolumn{2}{|l|}{ Surgery } \\
\hline Lumpectomy & $311(50 \%)$ \\
\hline Mastectomy & $314(50 \%)$ \\
\hline \multicolumn{2}{|l|}{ Axillary surgery } \\
\hline Axillary dissection & $200(39 \%)$ \\
\hline Sentinel biopsy & $315(61 \%)$ \\
\hline Radiation treatment-yes & $476(76 \%)$ \\
\hline Anti-HER-2 therapy-yes (of those who were HER-2 positive, $N=99$ ) & $93(94 \%)$ \\
\hline \multicolumn{2}{|l|}{ Chemotherapy treatment (any chemotherapy) } \\
\hline No & $176(28 \%)$ \\
\hline Yes & $449(72 \%)$ \\
\hline \multicolumn{2}{|l|}{ Chemotherapy timing } \\
\hline Adjuvant & $166(37 \%)$ \\
\hline Neoadjuvant & $283(63 \%)$ \\
\hline \multicolumn{2}{|l|}{ Chemotherapy regimen (with or without endocrine therapy/ET) } \\
\hline Anthracycline-based & $330(73 \%)$ \\
\hline Non-anthracycline & $119(27 \%)$ \\
\hline \multicolumn{2}{|l|}{ Chemotherapy alone (no ET) } \\
\hline No & $453(73 \%)$ \\
\hline Yes & $172(27 \%)$ \\
\hline Anthracycline-based & $119(69 \%)$ \\
\hline Not anthracycline-based & $53(31 \%)$ \\
\hline
\end{tabular}


Table 1 (continued)

\begin{tabular}{ll}
\hline Variable & All $(N=625)$ \\
\hline Endocrine therapy (ET, with or without chemotherapy) & $172(28 \%)$ \\
No ET & $453(72 \%)$ \\
Any ET & $162(36 \%)$ \\
Tamoxifen only & $230(51 \%)$ \\
Aromatase Inhibitor (AI) only & $61(13 \%)$ \\
Tamoxifen/AI (sequential) & \\
Endocrine therapy alone (no chemotherapy) & $449(72 \%)$ \\
No & $176(28 \%)$ \\
Yes & $37(21 \%)$ \\
Tamoxifen alone & $120(68 \%)$ \\
AI alone & $19(11 \%)$ \\
Tamoxifen/AI (sequential) & \\
Chemotherapy followed by endocrine therapy & $348(56 \%)$ \\
No & $277(44 \%)$ \\
Yes & $211(76 \%)$ \\
Anthracycline-based followed by ET & $66(24 \%)$ \\
Non-anthracycline followed by ET &
\end{tabular}

Percentages may not add exactly to $100 \%$ due to rounding

${ }^{\text {a }}$ Some women were pre-menopausal at $\mathrm{BC}$ diagnosis but became post-menopausal prior to ET start

women across most treatment plans (see Appendix 2 for further details).

\section{Discussion}

The current study builds on findings from our earlier research pertaining to weight trajectories in women with HR positive early breast cancer during the first 2 years of adjuvant endocrine treatment $[17,18]$. The expanded sample for the current analysis includes patients whose tumors were HR negative, including women with triple negative breast cancer. As we have found in our previous studies, one-third of patients had relatively stable weight $\pm 2 \mathrm{~kg}$ at 2 years and one-third lost $>2 \mathrm{~kg}$, net change at 2 years post-primary treatment. Patients remained mostly within the same BMI category as they were at diagnosis. However, $68 \%$ of premenopausal and $40 \%$ of post-menopausal women gained weight that moved them into a higher BMI category. This weight gain needs to be considered within the context that most patients in our study were overweight $(27 \%)$ or obese (40\%) at diagnosis.

In our current analysis, we identify weight trajectories within specific treatment plans that include or omit antiHER-2 therapy and different combinations of chemotherapy and endocrine treatment. We provide a level of specificity that could be useful in the clinic setting when a patient asks: "Will this treatment plan cause me to gain weight?" Our data can be reassuring that weight gain is not universal, but also that certain treatment plans coupled with menopausal status warrant attention to the potential for substantial weight gain. Our figures may be especially helpful in these patient-clinician discussions.

In unadjusted analysis of risk factors for $>2 \mathrm{~kg}$ weight gain, there is the pervasive influence of menopausal status on all of the significant variables. Specifically, younger age at diagnosis is associated with more aggressive forms of breast cancer (higher tumor stage and grade) [20, 21] compared to older women [22-25], and hence greater likelihood of neoadjuvant chemotherapy with longer duration anthracycline-based chemotherapy regimens [26]. Post-menopausal patients are more likely to have lower stage, hormone receptor-positive tumors and frequently receive only adjuvant endocrine therapy [27-29]. Our findings point to systemic treatments used for higher stage and more biologically aggressive tumors as risk factors for weight gain [30]. Our findings are consistent with other studies identifying younger age and/or pre-menopausal status at breast diagnosis as risk factors for weight gain [30-34]. Transitioning from pre- to post-menopausal status during treatment did not have a significant impact on weight gain, nor did receipt of anti-HER-2 therapy.

The question remains as to why chemotherapy, especially the longer duration regimens, is associated with weight gain. One possibility is the severity of chemotherapy-related toxicities [35] that may discourage engagement in levels of physical activity that are essential to avoiding weight gain. Specifically, fatigue is a common side effect of chemotherapy, with patient-reported fatigue of moderate/severe/ very severe toxicity ranging from $48 \%$ for TC regimens 
All patients

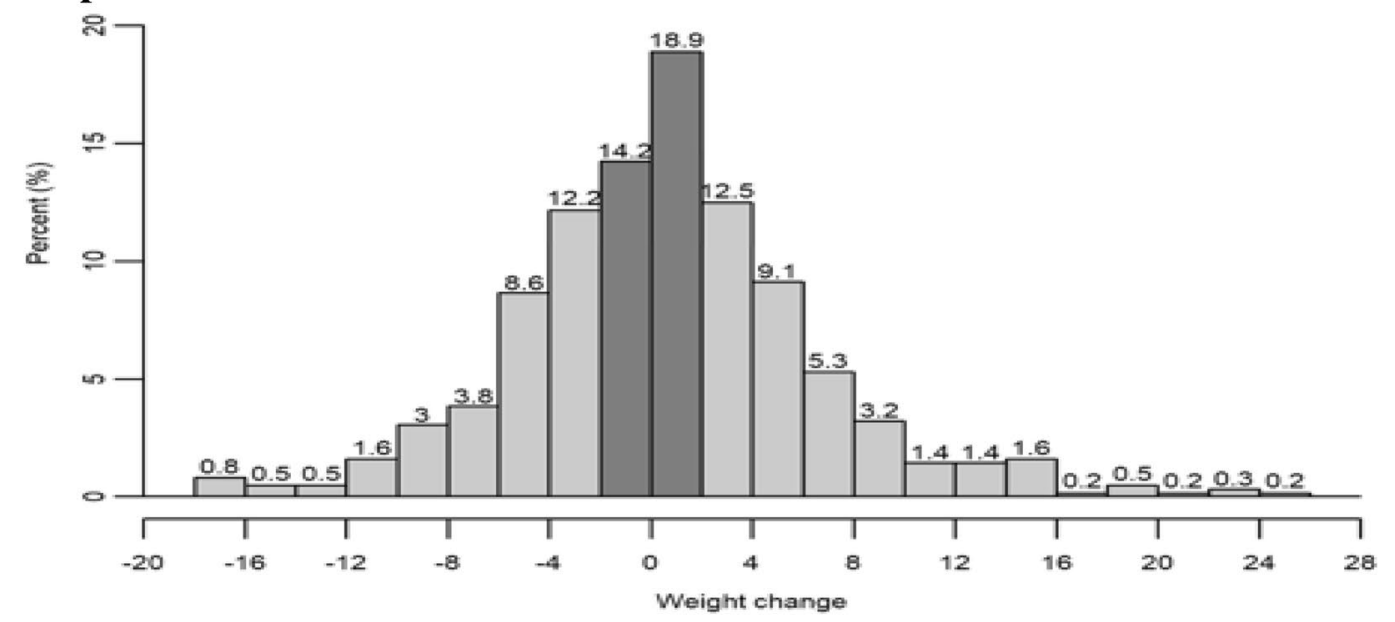

Pre-menopausal patients

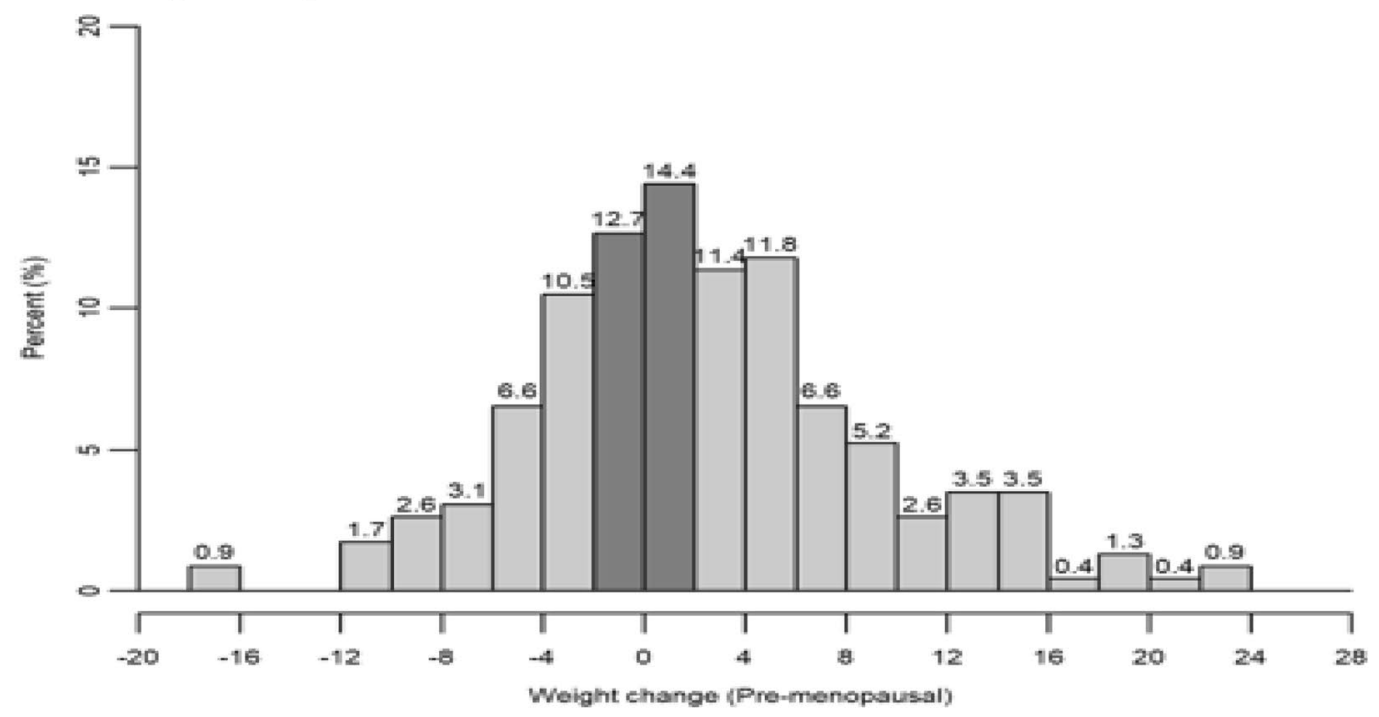

\section{Post-menopausal}

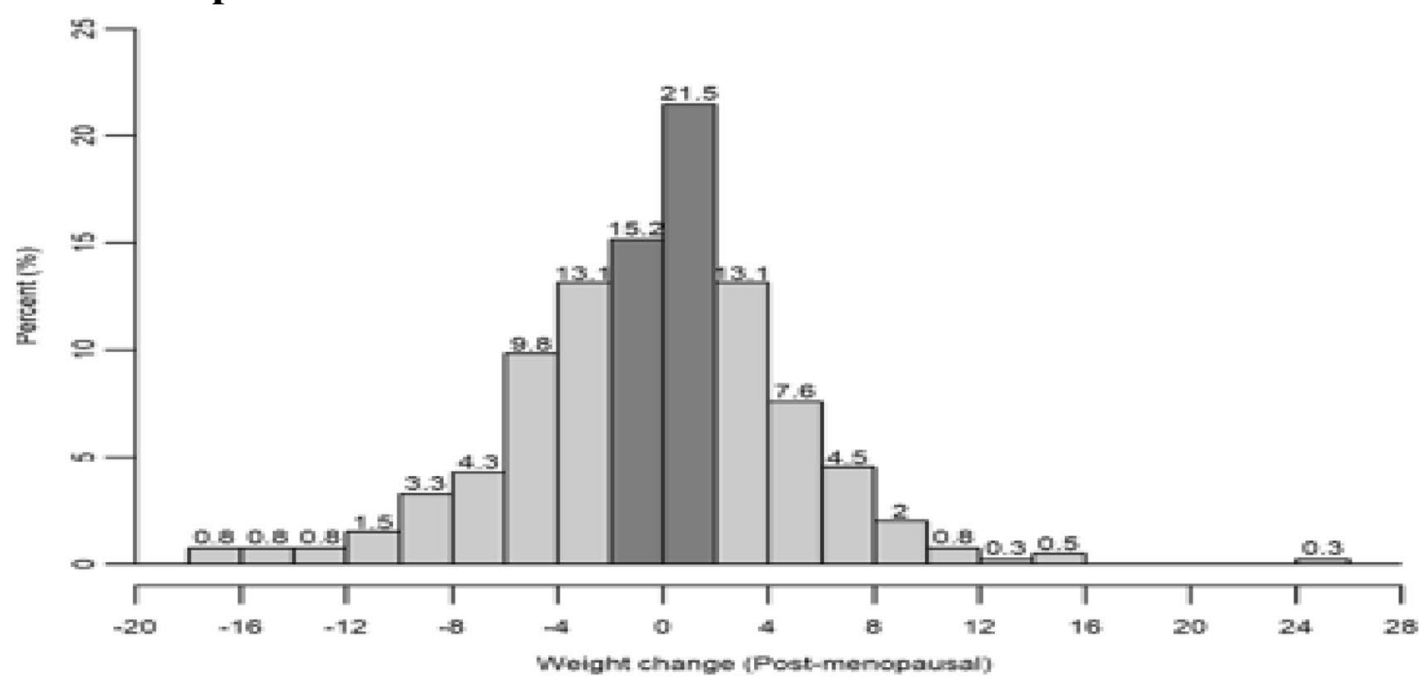

Fig. 1 Weight change at 2 years: $\mathrm{x}$-axis in kilograms $(\mathrm{kg})$, each bar in $2 \mathrm{~kg}$ increments $(\%)$, and shaded bars are stable weight ( $\pm 2 \mathrm{~kg})$ 
BMI categories at diagnosis and at 2 years $(\%)$, all patients $(\mathrm{N}=625)$

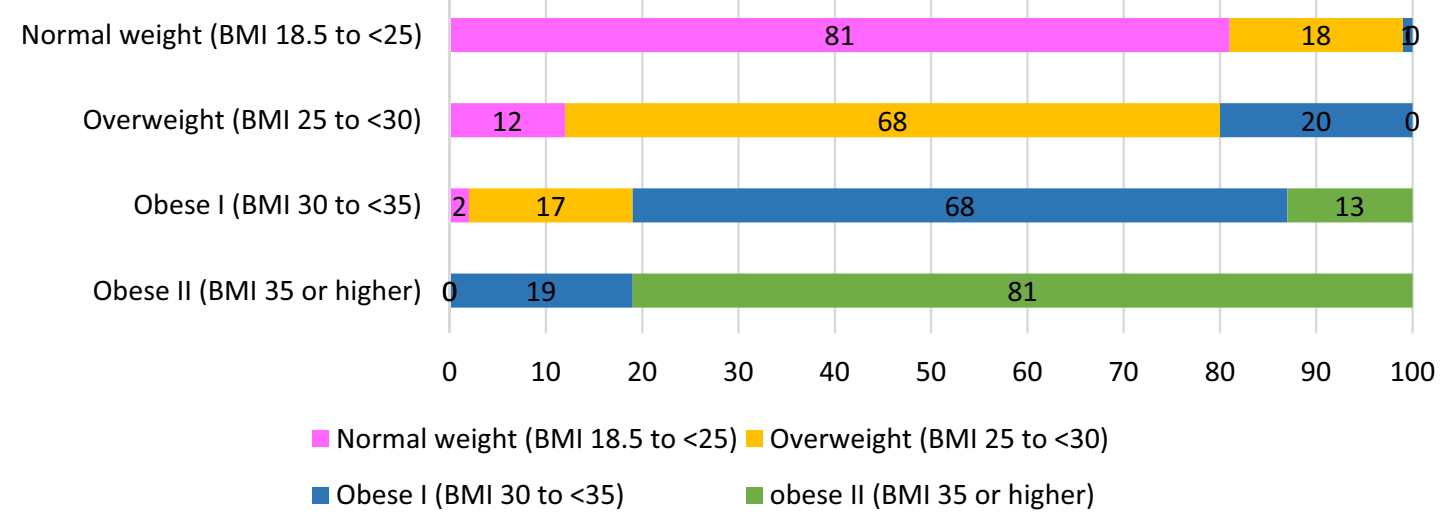

BMI categiries at baseline and at 2 years $(\%)$, pre-menopausal patients $(\mathrm{N}=229)$

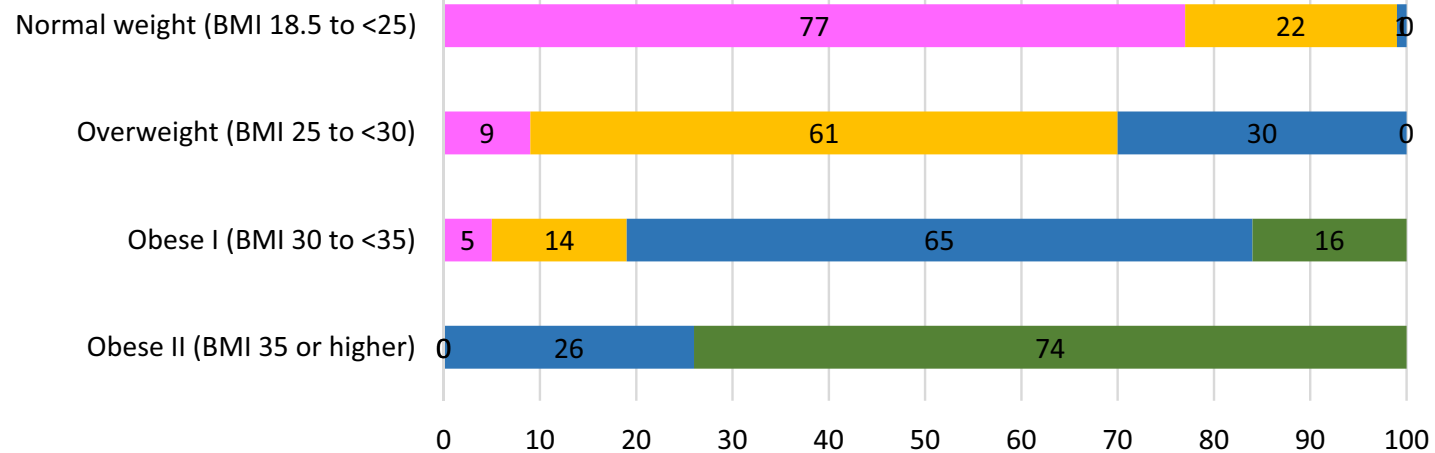

$\square$ Normal weight (BMI 18.5 to <25) $\square$ Overweight (BMI 25 to <30)

- Obese I (BMI 30 to $<35) \quad$ obese II (BMI 35 or higher)

BMI categories at baseline and at 2 years $(\%)$, post-menopausal patients $(\mathrm{N}=396)$

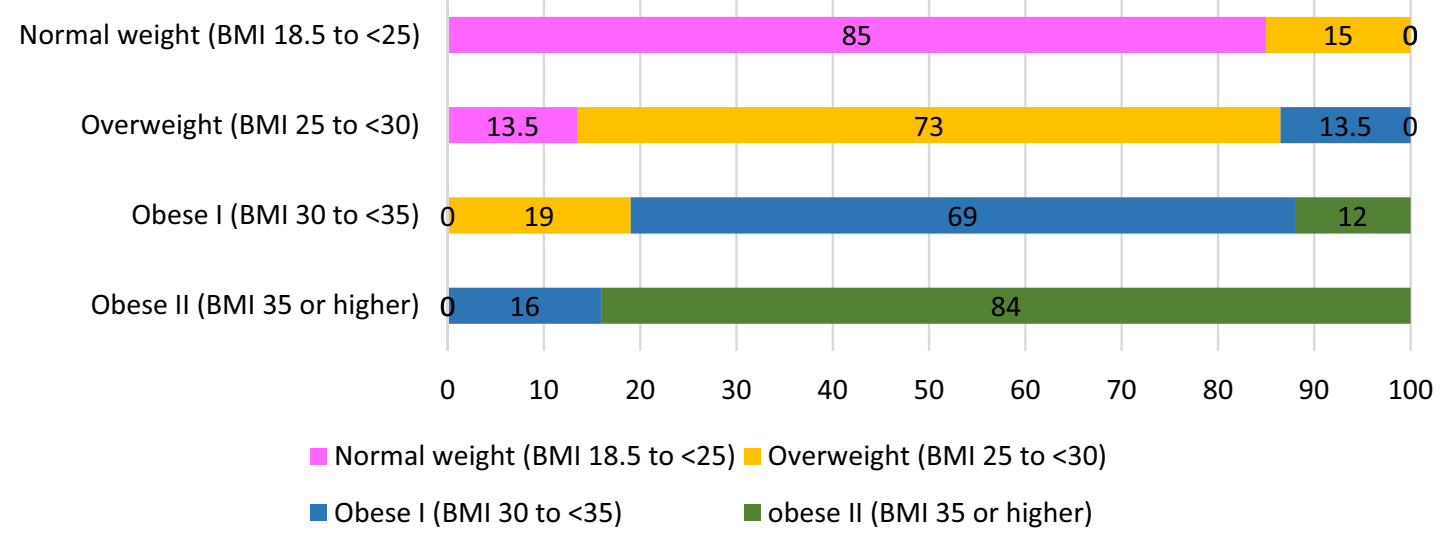

Legend: The y axis represents BMI category at breast cancer diagnosis and the colors represent BMI category at two years post diagnosis.

Fig. 2 Body mass index (BMI) categories at diagnosis and at 2 years post-treatment. The y-axis represents BMI category at breast cancer diagnosis and the colors represent BMI category at 2 years post-diagnosis 
Table 2 Weight change from diagnosis to 2 years post-primary treatment, relative risk for $>2 \mathrm{~kg}$ weight gain relative to weight loss $>2 \mathrm{~kg} / \mathrm{stable}$ weight $\pm 2 \mathrm{~kg}(N=625)$

\begin{tabular}{|c|c|c|c|c|c|}
\hline Variable & Weight loss $>2 \mathrm{~kg}$ & Stable weight $\pm 2 \mathrm{~kg}$ & $\begin{array}{l}>2 \mathrm{~kg} \text { weight gain } \\
N=219(35 \%)\end{array}$ & $\begin{array}{l}\text { Relative risk } \\
>2 \mathrm{~kg} \text { weight gain }{ }^{\mathrm{a}}\end{array}$ & $p$ value \\
\hline \multicolumn{6}{|l|}{ Race } \\
\hline White & $135(31 \%)$ & $152(34 \%)$ & $156(35 \%)$ & & - \\
\hline Other & $58(32 \%)$ & $60(33 \%)$ & $62(34 \%)$ & $1.02(0.81,1.30)$ & 0.85 \\
\hline \multicolumn{6}{|l|}{ Menopausal status at BC diagnosis } \\
\hline Pre-menopausal & $58(35 \%)$ & $64(28 \%)$ & $107(47 \%)$ & $1.65(1.34,2.04)$ & $<.0001$ \\
\hline Post-menopausal & $136(34 \%)$ & $148(37 \%)$ & $112(28 \%)$ & & - \\
\hline Weight at breast cancer diagnosis (kilograms) & $84(\mathrm{SD} 19.0)$ & $74(\mathrm{SD} 17.0)$ & $76(\mathrm{SD} 18.0)$ & $1.00(0.99,1.00)$ & 0.2 \\
\hline Body Mass Index (BMI) at diagnosis, mean (SD) & $31(\mathrm{SD} 6.8)$ & $27(\mathrm{SD} 6.0)$ & 29 (SD 6.6) & $0.97(0.97,1.01)$ & 0.27 \\
\hline \multicolumn{6}{|l|}{ BMI category at diagnosis } \\
\hline Normal (BMI 18.5 to $<25$ ) & $38(19 \%)$ & $92(45 \%)$ & $75(37 \%)$ & $0.99(0.97,1.01)$ & 0.26 \\
\hline Overweight $(\mathrm{BMI} 25$ to $<30)$ & $47(28 \%)$ & $61(36 \%)$ & $63(37 \%)$ & $1.01(0.77,1.31)$ & 0.96 \\
\hline Obese I (BMI 30 to <35) & $52(40 \%)$ & $37(28 \%)$ & $42(32 \%)$ & $0.88(0.64,1.19)$ & 0.4 \\
\hline Obese II (BMI 35 and above) & $57(49 \%)$ & $21(18 \%)$ & $38(33 \%)$ & $0.90(0.65,1.23)$ & 0.49 \\
\hline \multicolumn{6}{|l|}{ HER-2 } \\
\hline Negative & $165(32 \%)$ & $173(33 \%)$ & $180(35 \%)$ & & - \\
\hline Positive & $26(26 \%)$ & $35(35 \%)$ & $38(38 \%)$ & $1.10(0.84,1.46)$ & 0.48 \\
\hline \multicolumn{6}{|l|}{ Hormone receptor (HR) } \\
\hline Negative & $29(25 \%)$ & $39(34 \%)$ & $46(40 \%)$ & $1.19(0.92,1.54)$ & 0.18 \\
\hline Positive & $465(32 \%)$ & $173(34 \%)$ & $173(34 \%)$ & & - \\
\hline \multicolumn{6}{|l|}{ Breast surgery } \\
\hline Mastectomy & $97(31 \%)$ & $101(32 \%)$ & $116(37 \%)$ & $1.12(0.90,1.38)$ & 0.32 \\
\hline Lumpectomy & $97(31 \%)$ & $111(36 \%)$ & $103(33 \%)$ & & \\
\hline \multicolumn{6}{|l|}{ Axillary surgery } \\
\hline Axillary dissection & $64(32 \%)$ & $65(33 \%)$ & $71(35 \%)$ & $1.11(0.87,1.42)$ & 0.42 \\
\hline Sentinel biopsy & $100(32 \%)$ & $114(36 \%)$ & $101(32 \%)$ & & - \\
\hline \multicolumn{6}{|l|}{ Radiation } \\
\hline No & $46(31 \%)$ & $50(34 \%)$ & $53(36 \%)$ & & - \\
\hline Yes & $148(31 \%)$ & $162(34 \%)$ & $166(35 \%)$ & $0.98(0.76,1.26)$ & 0.88 \\
\hline \multicolumn{6}{|l|}{ Anti-HER-2 therapy } \\
\hline No & $167(32 \%)$ & $176(34 \%)$ & $181(34 \%)$ & & - \\
\hline Yes & $24(26 \%)$ & $32(34 \%)$ & $37(40 \%)$ & $1.15(0.87,1.52)$ & 0.31 \\
\hline \multicolumn{6}{|l|}{ Chemotherapy } \\
\hline No & $63(36 \%)$ & $64(36 \%)$ & $49(28 \%)$ & & - \\
\hline Yes & $131(29 \%)$ & $148(33 \%)$ & $170(38 \%)$ & $1.36(1.04,1.77)$ & 0.02 \\
\hline \multicolumn{6}{|l|}{ Chemotherapy timing } \\
\hline Adjuvant & $52(31 \%)$ & $59(36 \%)$ & $55(33 \%)$ & & \\
\hline Neoadjuvant & $79(28 \%)$ & $89(31 \%)$ & $115(41 \%)$ & $1.23(0.95,1.59)$ & 0.12 \\
\hline \multicolumn{6}{|l|}{ Chemotherapy with or without ET } \\
\hline Non-anthracycline & $34(29 \%)$ & $47(40 \%)$ & $38(32 \%)$ & & \\
\hline Anthracycline-based & $97(29 \%)$ & $101(31 \%)$ & $132(40 \%)$ & $1.25(0.93,1.68)$ & 0.13 \\
\hline \multicolumn{6}{|l|}{ Chemotherapy alone (no ET) } \\
\hline Anthracycline-based & $31(26 \%)$ & $38(32 \%)$ & $50(42 \%)$ & $1.01(0.69,1.48)$ & 0.95 \\
\hline Non-anthracycline-based & $13(25 \%)$ & $18(34 \%)$ & $22(42 \%)$ & & - \\
\hline \multicolumn{6}{|l|}{ Endocrine therapy (any ET) } \\
\hline None & $44(26 \%)$ & $56(33 \%)$ & $72(42 \%)$ & & - \\
\hline Yes & $150(33 \%)$ & $156(34 \%)$ & $147(32 \%)$ & $0.78(0.62,0.97)$ & 0.02 \\
\hline \multicolumn{6}{|l|}{ Endocrine therapy (with or without chemotherapy) } \\
\hline Tamoxifen & $51(32 \%)$ & $44(27 \%)$ & $67(41 \%)$ & & \\
\hline
\end{tabular}


Table 2 (continued)

\begin{tabular}{|c|c|c|c|c|c|}
\hline Variable & Weight loss $>2 \mathrm{~kg}$ & Stable weight $\pm 2 \mathrm{~kg}$ & $\begin{array}{l}>2 \mathrm{~kg} \text { weight gain } \\
N=219(35 \%)\end{array}$ & $\begin{array}{l}\text { Relative risk } \\
>2 \mathrm{~kg} \text { weight gain }{ }^{\mathrm{a}}\end{array}$ & $p$ value \\
\hline Aromatase Inhibitor (AI) only & $85(37 \%)$ & $84(37 \%)$ & $61(27 \%)$ & $0.64(0.48,0.85)$ & 0.002 \\
\hline Tamoxifen/AI (sequential) & $14(23 \%)$ & $28(46 \%)$ & $19(31 \%)$ & $0.75(0.50,1.14)$ & 0.18 \\
\hline \multicolumn{6}{|l|}{ Endocrine therapy alone (no chemotherapy) } \\
\hline Tamoxifen alone & $13(35 \%)$ & $13(35 \%)$ & $11(30 \%)$ & $1.08(0.61,1.92)$ & 0.79 \\
\hline Aromatase Inhibitor only & $44(37 \%)$ & $43(36 \%)$ & $33(28 \%)$ & & - \\
\hline Tamoxifen/AI (sequential) & $6(32 \%)$ & $8(42 \%)$ & $5(26 \%)$ & $0.96(0.43,2.14)$ & 0.91 \\
\hline \multicolumn{6}{|l|}{ Chemotherapy followed by endocrine therapy } \\
\hline Anthracycline-based followed by ET & $66(31 \%)$ & $63(30 \%)$ & $82(39 \%)$ & $1.60(1.01,2.54)$ & 0.04 \\
\hline Non-anthracycline-based followed by ET & $21(32 \%)$ & $29(44 \%)$ & $16(24 \%)$ & & \\
\hline
\end{tabular}

Italics indicate statistically significant $p$ values

${ }^{\text {a}}$ Relative risk compared to stable weight $\pm 2 \mathrm{~kg} /$ weight loss $>2 \mathrm{~kg}$

to $83 \%$ for AC-T and $78 \%$ for AC-TC regimens ( $p=.001)$ [35]. Similarly, moderate or higher patient-reported chemotherapy-induced peripheral neuropathy (CIPN), which may impede physical activity, ranges from $10 \%$ for TC regimens to $48 \%$ for AC-T and $50 \%$ for AC-TC regimens $(p<.0001)$ [35]. We have previously reported that the total number of patient-reported symptoms rated moderately severe or higher ranges from 4.3 for TC compared to 6.2 for AC-T and 6.8 for AC-TC [35], which can make engagement in even low levels of physical activity challenging [36]. Most symptoms abate after chemotherapy; however, fatigue and CIPN can linger for years, contributing to the decreased physical activity often observed in women diagnosed with breast cancer $[37,38]$. As a consequence, women on anthracycline-taxane regimens may be at especially high risk for decreased physical activity and, hence, weight gain.

The strengths of our study include a large sample $(N=625)$ of women seen in clinical practice, without the potential bias of women recruited into a study. The high proportion of non-white women (29\%) further enhances the generalizability of our study. Our focus is chemotherapy regimens commonly used in current clinical practice, and include analyses of different chemotherapy regimens with or without endocrine therapy, and endocrine therapy alone. Weight trajectories are provided with great specificity for various combinations of adjuvant systemic therapy, overall and by menopausal status.

A limitation of our study is the lack of electronic health record data pertaining to exercise, diet, and weight management efforts, as potential moderators of weight trajectories, and notwithstanding tumor severity and associated treatments $[33,39,40]$. For example, from physical activity information, we might learn if women receiving certain chemotherapy regimens decrease exercise more than other regimens, specifically anthracycline-taxane regimens which are associated with more severe side effects [35]. It is also a limitation of our study that we did not have data on weight trajectories prior to breast cancer diagnosis to include in our analysis of potential risk factors.

We also note that our sample is greatly under-represented by women with Stage 0 breast cancer (DCIS) and women who received anti-estrogen therapy only. And, our sample was drawn from just one site that is affiliated with a large academic institution. These considerations may limit the generalizability of our study to patients with more diverse geographic backgrounds and cultures.

To the extent adverse changes in body composition emerge as risk factors for breast cancer prognosis and overall survival [41-47], weight gain in breast cancer survivorship warrants attention in clinical practice. At a minimum, it is concerning that women with early breast cancer who are benefitting from ever-improving survivorship often succumb to comorbidities that are obesity-related, such as diabetes, hypertension, cardiovascular disease, and metabolic syndrome that contribute to CVD risk $[48,49]$ and reduce their overall survival [50]. These diseases are more often seen in overweight or obese patients compared to normal weight patients [51-55], and overall comorbidity burden is higher in women with breast cancer whose BMI is greater than 30 to those with a lower BMI $[56,57]$.

The one-third of women in our study who gained weight in survivorship and the $40 \%$ of women who were obese at diagnosis are likely to be in greatest need of timely referral to energy balance/weight management programs or intervention studies [58, 59]. Adoption of healthy lifestyles is a major challenge for women who have been sedentary and overweight or obese for long periods of time. For these women, the diagnosis of breast cancer can be a "teachable moment" for making changes in their lifestyle [60], especially with the recommendation and encouragement of their oncology clinician [61-63]. There is limited but promising evidence that physical activity and weight management 


\section{All patients $(\mathrm{N}=625)$}

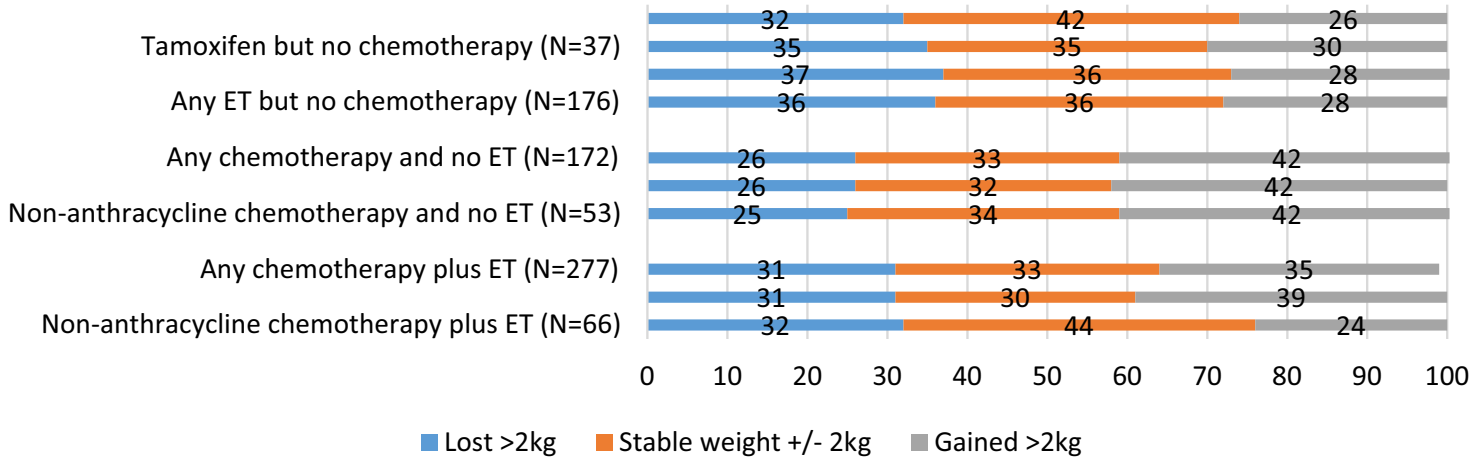

Pre-menopausal patients $(\mathrm{N}=\mathbf{2 2 9})$

Tamoxifen but no chemotherapy ( $\mathrm{N}=15)$

Any ET but no chemotherapy $(\mathrm{N}=17)$

Any chemotherapy and no $\mathrm{ET}(\mathrm{N}=82)$

Anthracycline-based chemotherapy and no ET ( $N=69)$

Non-anthracycline chemotherapy and no ET $(\mathrm{N}=13)$

Any chemotherapy plus ET ( $\mathrm{N}=130)$

Anthracycline-based chemotherapy plus ET ( $N=113$ )

Non-anthracycline chemotherapy plus ET ( $\mathrm{N}=17)$

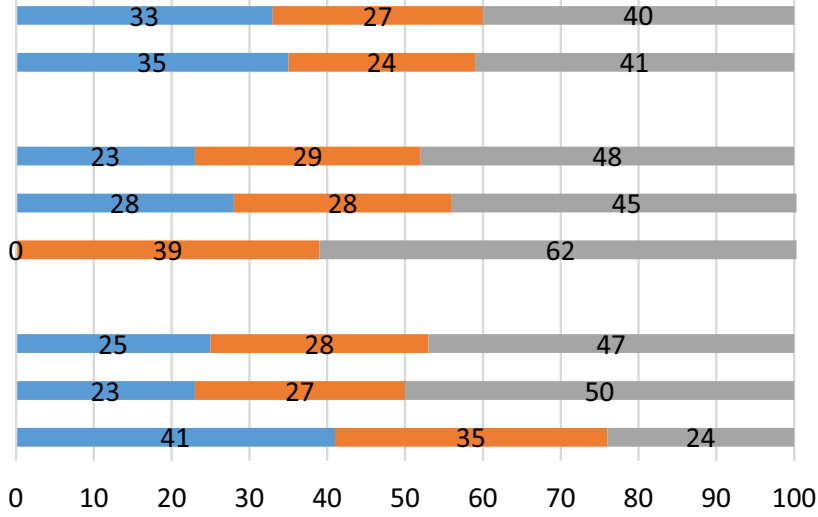

- Lost $>2 \mathrm{~kg}$ Stable weight + /- $2 \mathrm{~kg} \quad$ Gained $>2 \mathrm{~kg}$

Post-menopausal patients ( $N=396)$

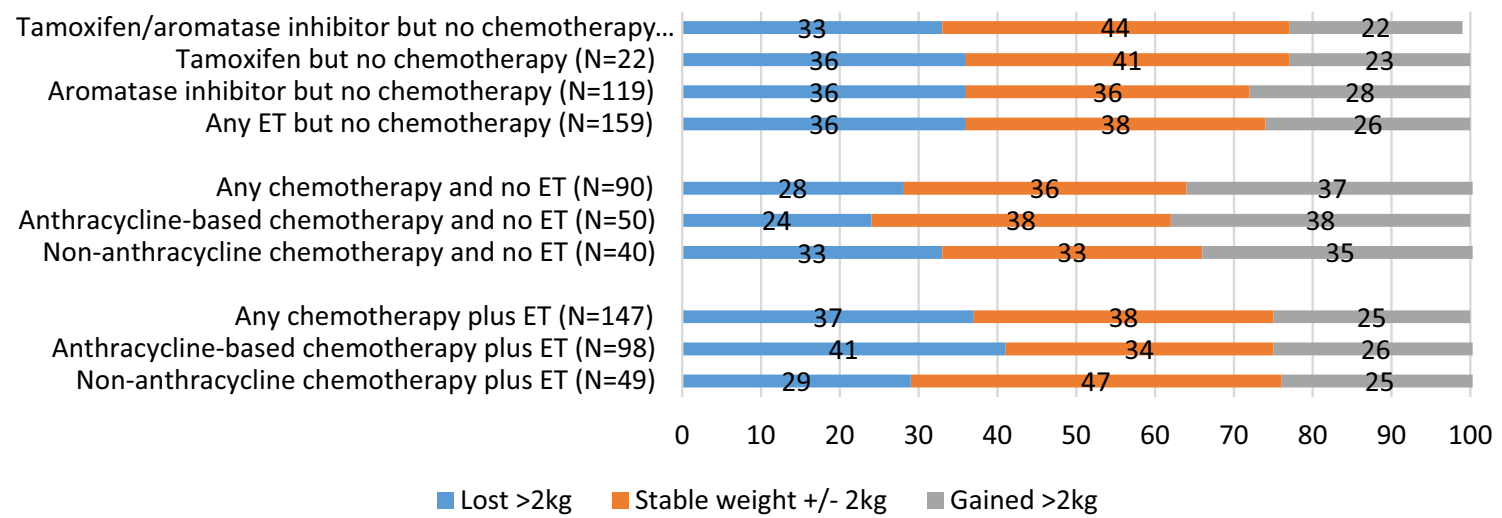

Fig. 3 Weight categories by treatment plan—percent of patients who lost $>2 \mathrm{~kg}$, had stable weight $\pm 2 \mathrm{~kg}$, or gained $>2 \mathrm{~kg}$ at 2 years postprimary treatment

conversations between patients and their oncology clinician are feasible during routine clinic visits $[64,65]$. It is timely to consider how and when to incorporate patientcentered weight management counseling and referral to weight management specialists into breast cancer care and rehabilitation $[14,16,66,67]$. 
Funding This study was supported by the Breast Cancer Research Foundation (New York), UNC Lineberger Comprehensive Cancer Center/University Cancer Research Fund, and the UNC SPORE in Breast Cancer (CA58223). Dr. Shachar's fellowship at UNC was supported by the Friends of Rambam Medical Center and The J\&G Zukier Medical Fund Donation, Haifa, Israel.

\section{Compliance with ethical standards}

Conflict of interest The authors declare they have no conflict of interest.

Ethical approval All procedures performed in studies involving human participants were in accordance with the ethical standards of the institutional and/or national research committee and with the 1964 Helsinki declaration and its later amendments or comparable ethical standards.

Informed consent This study did not entail direct contact with humans and therefore did not entail obtaining informed consent.

\section{References}

1. Goodwin PJ, Ennis M, Pritchard KI, McCready D, Koo J et al (1999) Adjuvant treatment and onset of menopause predict weight gain after breast cancer diagnosis. J Clin Oncol 17(1):120-129

2. Rock CL, Flatt SW, Newman V, Caan BJ, Haan MN et al (1999) Factors associated with weight gain in women after diagnosis of breast cancer. Women's Healthy Eating and Living Study Group. J Am Diet Assoc 10:1212-1221

3. Demark-Wahnefried W, Rimer BK, Winer EP (1997) Weight gain in women diagnosed with breast cancer. J Am Diet Assoc 97(5):519-529 (quiz 527-518)

4. Saquib N, Flatt SW, Natarajan L, Thomson CA, Bardwell WA et al (2007) Weight gain and recovery of pre-cancer weight after breast cancer treatments: evidence from the Women's healthy Eating and Living (WHEL) study. Breast Cancer Res Treat 105(2):177-186

5. Vance V, Mourtzakis M, McCargar L, Hanning R (2011) Weight gain in breast cancer survivors: prevalence, pattern and health consequences. Obes Rev 12(4):282-294

6. van den Berg MM, Winkels RM, de Kruif JT et al (2017) Weight change during chemotherapy in breast cancer patients: a metaanalysis. BMC Cancer 17(1):259

7. Dixon JK, Moritz DA, Baker FL (1978) Breast cancer and weight gain: an unexpected finding. Oncol Nurs Forum 5(3):5-7

8. Levine EG, Raczynski JM, Carpenter JT (1991) Weight gain with breast cancer adjuvant treatment. Cancer 67(7):1954-1959

9. Gross AL, May BJ, Axilbund JE, Armstrong DK, Roden RB, Visvanathan K (2015) Weight change in breast cancer survivors compared to cancer-free women: a prospective study in women at familial risk of breast cancer. Cancer Epidemiol Biomark Prev 24(8):1262-1269

10. Heideman WH, Russell NS, Gundy C, Rookus MA, Voskuil DW (2009) The frequency, magnitude and timing of post-diagnosis body weight gain in Dutch breast cancer survivors. Eur J Cancer 45:119-126

11. Tredan O, Bajard A, Meunier A, Roux P, Fiorletta I et al (2010) Body weight change in women receiving adjuvant chemotherapy for breast cancer: a French prospective study. Clin Nutr (Edinburgh, Scotland) 29(2):187-191

12. Makari-Judson G, Judson CH, Mertens WC (2007) Longitudenal patterns of weight gain after breast cancer diagnosis: observations beyond the first year. Breast 13(3):258-265
13. Anderson AS, Key TJ, Norat T et al (2015) European code against cancer 4th edition: obesity, body fatness and cancer. Cancer Epidemiol 39(Suppl 1):S34-S45

14. Denlinger CS, Ligibel JA, Are M et al (2014) Survivorship: nutrition and weight management, Version 2.2014 Clinical practice guidelines in oncology. J Natl Compr Cancer Netw 12(10):1396-1406

15. Ligibel JA, Wollins D (2016) American Society of Clinical Oncology obesity initiative: rationale, progress, and future directions. J Clin Oncol 34(35):4256-4260

16. Ligibel JA, Alfano CM, Courneya KS et al (2014) American Society of Clinical Oncology position statement on obesity and cancer. J Clin Oncol 32(31):3568-3574

17. Nyrop KA, Deal AM, Lee JT et al (2017) Weight changes in postmenopausal breast cancer survivors over 2 years of endocrine therapy: a retrospective chart review. Breast Cancer Res Treat 162:375-388

18. Nyrop KA, Deal AM, Lee JT et al (2018) Weight gain in hormone receptor-positive $(\mathrm{HR}+)$ early-stage breast cancer: is it menopause or something else. Breast Cancer Res Treat 167(1):235-248

19. Harris PA, Taylor R, Thielke R, Payne J, Gonzalez N, Conde JG (2009) Research electronic data capture (REDCap)—a metadata-driven methodology and workflow process for providing translational research informatics support. J Biomed Inform 2009(42):377-381

20. Chollet-Hinton L, Anders CK, Tse CK et al (2016) Breast cancer biologic and etiologic heterogeneity by young age and menopausal status in the Carolina Breast Cancer Study: a case-control study. Breast Cancer Res 18(1):79

21. Clarke CA, Keegan TH, Yang J et al (2012) Age-specific incidence of breast cancer subtypes: understanding the black-white crossover. J Natl Cancer Inst 104(14):1094-1101

22. Benz CC (2008) Impact of aging on the biology of aging. Crit Rev Oncol Hematol 66(1):65-74

23. Eppenberger-Castori S, Moore DH Jr, Thor AD et al (2002) Ageassociated biomarker profiles of human breast cancer. Int J Biochem Cell Biol 34(11):1318-1330

24. Howlader N, Altekruse SF, Li CI et al (2014) US incidence of breast cancer subtypes defined by joint hormone receptor and HER2 status. J Natl Cancer Inst. https://doi.org/10.1093/jnci/ dju055

25. Jenkins EO, Deal AM, Anders CK et al (2014) Age-specific changes in intrinsic breast cancer subtypes: a focus on older women. Oncologist 19(10):1076-1083

26. Shah AN, Gradishar WJ (2018) Adjuvant anthracyclines in breast cancer: what is their role? Oncologist 23(10):1153-1161

27. Taylor WC, Muss HB (2010) Recent advances: adjuvant therapy for older women with breast cancer. Cancer J 16(4):289-293

28. Schiavon G, Smith IE (2014) Status of adjuvant endocrine therapy for breast cancer. Breast Cancer Res 16(2):206

29. Dowsett M, Cuzick J, Ingle J et al (2010) Meta-analysis of breast cancer outcomes in adjuvant trials of aromatase inhibitors versus tamoxifen. J Clin Oncol 28(3):509-518

30. Chaudhary LN, Wen S, Xiao J, Swisher AK, Kurian S, Abraham J (2014) Weight change associated with third-generation adjuvant chemotherapy in breast cancer patients. J Commun Support Oncol 12(10):355-360

31. Befort CA, Austin H, Klemp JR (2011) Weight control needs and experiences among rural breast cancer survivors. Psychooncology 20(10):1069-1075

32. Caan B, Sternfeld B, Gunderson E, Coates A, Quesenberry C, Slattery ML (2005) Life After Cancer Epidemiology (LACE) Study: a cohort of early stage breast cancer survivors (United States). Cancer Causes Control 16(5):545-556

33. Irwin ML, McTiernan A, Baumgartner RN, Bernstein L, Gilliland FD, Ballard-Barbash R (2005) Changes in body fat and weight 
after a breast cancer diagnosis: influence of demographic, prognostic, and lifestyle factors. J Clin Oncol 23(4):774-782

34. Sadim M, Xu Y, Selig K, et al. Clinical and genetic predictors of weight gain in patients diagnosed with breast cancer. Cancer. 2017

35. Nyrop KA, Deal AM, Shachar SS, et al. Patient-reported toxicities during chemotherapy regimens in current clinical practice for early breast cancer. The Oncologist. 2018; [accepted for publication December 2018]

36. Nyrop KA, Deal AM, Choi SK et al (2018) Measuring and understanding adherence in a home-based exercise intervention during chemotherapy for early breast cancer. Breast Cancer Res Treat 168(1):43-55

37. Kwan ML, Sternfeld B, Ergas IJ et al (2012) Change in physical activity during active treatment in a prospective study of breast cancer survivors. Breast Cancer Res Treat 131(2):679-690

38. Harrison S, Hayes SC, Newman B (2009) Level of physical activity and characteristics associated with change following breast cancer diagnosis and treatment. Psycho-Oncology 18:387-394

39. Thompson CL, Owusu C, Nock NL, Li L, Berger NA (2014) Race, age, and obesity disparities in adult physical activity levels in breast cancer patients and controls. Front Public Health 2:150

40. Vagenas D, DiSipio T, Battistutta D et al (2015) Weight and weight change following breast cancer: evidence from a prospective, population-based, breast cancer cohort study. BMC Cancer 15(1):28

41. Chan DS, Vieira AR, Aune D et al (2014) Body mass index and survival in women with breast cancer-systematic literature review and meta-analysis of 82 follow-up studies. Ann Oncol 25(10):1901-1914

42. Azrad M, Demark-Wahnefried W (2014) The association between adiposity and breast cancer recurrence and survival: a review of the recent literature. Curr Nutr Rep 3(1):9-15

43. Druesne-Pecollo N, Touvier M, Barrandon E et al (2012) Excess body weight and second primary cancer risk after breast cancer: a systematic review and meta-analysis of prospective studies. Breast Cancer Res Treat 135(3):647-654

44. Jiralerspong S, Goodwin PJ (2016) Obesity and breast cancer prognosis: evidence, challenges, and opportunities. J Clin Oncol 34(35):4203-4216

45. Niraula S, Ocana A, Ennis M, Goodwin PJ (2012) Body size and breast cancer prognosis in relation to hormone receptor and menopausal status: a meta-analysis. Breast Cancer Res Treat 134(2):769-781

46. Playdon MC, Bracken MB, Sanft TB, Ligibel JA, Harrigan M, Irwin ML (2015) Weight gain after breast cancer diagnosis and all-cause mortality: systematic review and meta-analysis. J Natl Cancer Inst 107(12):djv275

47. Sheean PM, Hoskins K, Stolley M (2012) Body composition changes in females treated for breast cancer: a review of the evidence. Breast Cancer Res Treat 135(3):663-680

48. Gernaat SAM, Boer JMA, van den Bongard DHJ et al (2018) The risk of cardiovascular disease following breast cancer by Framingham risk score. Breast Cancer Res Treat 170(1):119-127

49. Haque R, Prout M, Geiger AM et al (2014) Comorbidities and cardiovascular disease risk in older breast cancer survivors. Am J Manage Care 20(1):86-92

50. Patnaik JL, Byers T, DiGuiseppi C, Dabelea D, Denberg TD (2011) Cardiovascular disease competes with breast cancer as the leading cuase of death for older females diagnosed with breast cancer: a retrospective cohort study. Breast Cancer Res 13:R64

51. Peairs KS, Barone BB, Snyder CF et al (2011) Diabetes mellitus and breast cancer outcomes: a systematic review and meta-analysis. J Clin Oncol 29(1):40-46
52. Patnaik J, Byers T, Diguiseppi C, Denberg T, Dabelea D (2011) The influence of comorbidities on overall survival among older women diagnosed with breast cancer. J Natl Cancer Inst 103(14):1101-1111

53. Thomson CA, Thompson PA, Wright-Bea J, Nardi E, Frey GR, Stopeck A (2009) Metabolic syndrome and elevated C-reactive protein in breast cancer survivors on adjuvant hormone therapy. J Womens Health (Larchmt) 18(12):2041-2047

54. Lohmann AE, Ennis M, Taylor SK, Goodwin PJ (2017) Metabolic factors, anthropometric measures, diet, and physical activity in long-term breast cancer survivors: change from diagnosis and comparison to non-breast cancer controls. Breast Cancer Res Treat 164(2):451-460

55. Kim A, Scharf K, Senthil M, Solomon N, Garberoglio C, Lum SS (2014) The prevalence of overweight and obesity in a breast clinic population: consideration for weight loss as a therapeutic intervention. Surg Obes Relat Dis 10(2):348-353

56. Braithwaite D, Moore DH, Satariano WA et al (2012) Prognostic impact of comorbidity among long-term breast cancer survivors: results from the LACE study. Cancer Epidemiol Biomark Prev 21(7):1115-1125

57. Leach CR, Weaver KE, Aziz NM et al (2015) The complex health profile of long-term cancer survivors: prevalence and predictors of comorbid conditions. J Cancer Surviv 9(2):239-251

58. Reeves MM, Terranova CO, Eakin EG, Demark-Wahnefried W (2014) Weight loss intervention trials in women with breast cancer: a systematic review. Obes Rev 15(9):749-768

59. Demark-Wahnefried W, Rogers LQ, Alfano CM et al (2015) Practical clinical interventions for diet, physical activity, and weight control in cancer survivors. CA Cancer J Clin 65(3):167-189

60. Alfano CM, Day JM, Katz ML et al (2009) Exercise and dietary change after diagnosis and cancer-related symptoms in long-term survivors of breast cancer: CALGB 79804. Psychooncology 18(2):128-133

61. Anderson AS, Mackison D, Boath C, Steele R (2013) Promoting changes in diet and physical activity in breast and colorectal cancer screening settings: an unexplored opportunity for endorsing healthy behaviors. Cancer Prev Res (Phila) 6(3):165-172

62. Hardcastle SJ, Cohen PA (2017) Effective physical activity promotion to survivors of cancer is likely to be home based and to require oncologist participation. J Clin Oncol 35(32):3635-3637

63. Demark-Wahnefried W, Aziz NM, Rowland JH, Pinto BM (2005) Riding the crest of the teachable moment: promoting long-term health after the diagnosis of cancer. J Clin Oncol 23(24):5814-5830

64. Nyrop KA, Deal AM, Williams GR, Guerard EJ, Pergolotti M, Muss HB (2016) Physical activity communication between oncology providers and patients with early-stage breast, colon, or prostate cancer. Cancer 122(3):470-476

65. Nyrop KA, Lee JT, Deal AM, Choi SK, Muss HB (2019) Weightrelated communications between oncology clinicians and women with obesity at early breast cancer diagnosis: findings from a review of the electronic health record. Nutrition Cancer. https:// doi.org/10.1080/01635581.2019.1645863

66. Demark-Wahnefried W, Campbell KL, Hayes SC (2012) Weight management and its role in breast cancer rehabilitation. Cancer 118(8 Suppl):2277-2287

67. Goodwin PJ (2010) Commentary on: "Effect of obesity on survival in women with breast cancer: systematic review and metaanalysis" (Melinda Protani, Michael Coory, Jennifer H. Martin). Breast Cancer Res Treat 123(3):637-640

Publisher's Note Springer Nature remains neutral with regard to jurisdictional claims in published maps and institutional affiliations. 